\title{
A New Operating Concept to Enhance Wells Turbine Performance
}

\author{
Hossam. S. Hamed*, Mohamed. A. Nawar ${ }^{\dagger}$, Rafea Mohamed Abd El-Maksoud
}

\begin{abstract}
Wells turbine is a self-rectifying turbine capable of converting pneumatic power of the periodically reversing flow (air or water) stream in oscillating ocean waving water column into mechanical energy. However, such turbines suffers from low aerodynamic efficiency, low power produced, and narrow operating range. To enhance the Wells turbine performance, the present work proposed that a new operating concept where the turbine is immersed in water. This gives the privilege of operating the turbine with a fluid having higher specific weight fluid instead of air. This paper presents a numerical investigation of the Wells turbine performance operating under steady unidirectional flow conditions. The studied parameters are the turbine efficiency, torque coefficient, and the turbine total pressure drop coefficient. The results are performed by solving numerically the steady 3D incompressible Reynolds Averaged NavierStokes equation (RANS) using ANSYS FLYENT v16.2 commercial code. The results demonstrate that a substantial improvement in the turbine performance where the maximum percentage increase in turbine efficiency is about 4 times its efficiency in air, and the maximum percentage increase in turbine power reaches to 4.5 times increase at flow coefficient of 0.275 . Furthermore, and a wider range of operation is achieved by using water instead of air as a working fluid which mean that the stall point is delayed. Using Wells turbine immersed in water is a promising issue for further investigations.
\end{abstract}

Keywords: Wells Turbine, Axial flow turbine, working fluid, Wave energy conversion, CFD simulation.

\section{Nomenclature}

$\begin{array}{clcl}\mathrm{C}_{\mathrm{T}} & \text { torque coefficient }(-) & U & \text { tangential velocity }(\mathrm{m} / \mathrm{s}) \\ c & \text { chord length }(\mathrm{m}) & v & \text { axial velocity }(\mathrm{m} / \mathrm{s}) \\ \mathrm{D} & \text { drag force }(\mathrm{N}) & W & \text { relative velocity }(\mathrm{m} / \mathrm{s}) \\ \mathbf{L} & \text { lift force }(\mathrm{N}) & \alpha & \text { angle of attack }\left({ }^{0}\right) \\ \Delta P_{0} & \text { total pressure drop }(\mathrm{Pa}) & \boldsymbol{\phi} & \text { flow coefficient }(-) \\ \mathrm{F}_{\theta} & \text { tangential force }(\mathrm{N}) & \eta & \text { efficiency }(-) \\ \mathrm{F}_{x} & \text { axial force }(\mathrm{N}) & \rho & \text { air density }\left(\mathrm{kg} / \mathrm{m}^{3}\right) \\ Q & \text { volume flow rate }\left(\mathrm{m}^{3} / \mathrm{s}\right) & \omega & \text { angular velocity }(\mathrm{rad} / \mathrm{s}) \\ R & \text { rotor tip radius }(\mathrm{m}) & \Delta P^{*} & \text { Pressure drop coefficient }(-) \\ T & \text { torque }(\mathrm{N} . \mathrm{m}) & * & \text { Non-dimensional parameter }\end{array}$

\footnotetext{
Demonstrator, Mechanical Power Engineering Department, Faculty of Engineering at Mataria, Helwan University, Egypt, eng.hossamsaed @ gmail.com

$\dagger$ Assistant Professor, Mechanical Power Engineering Department, Faculty of Engineering at Mattaria, Helwan University, Egypt.

* Associate Professor, Mechanical Power Engineering Department, Faculty of Engineering at Mattaria, Helwan University, Egypt.
} 


\section{Introduction}

The extensive depletion of the conventional sources of energy has forced the mankind to explore every possibilities lying beneath the nature. A new worldwide interest in renewable energy sources arose recently from the running out of traditional energy sources and the overall pollution growth. In the last two decades, efforts have been devoted, among all, to sea wave energy. Oceans contain a large amount of energy, and harnessing the energy is a challenging task because of several factors such as uncertainty of the sea wave or current and natural calamities, etc. OWC (oscillating water column), which is a wave energy system, uses an impulse or a reaction turbine to extract energy from the waves. Wave energy is a new promising source of renewable energy in Egypt. Recent investigations show that some locations in the north cost of Egypt are convenient for wave energy conversion (WEC) [1]. Wave energy devices based on the principle of oscillating water column (OWC) are the most practicable for wave energy conversion [2]. Raghunathan [2] presented an extensive review on the performance of the different types of Wells turbines generating energy from oscillating water columns. The Wells turbine is an axial flow self-rectifying low-pressure air turbine which rotates continuously in one direction. The turbine blades are constructed using symmetric air foil and the angle of attack on the airfoil is $90^{\circ}$.

Many authors have attempted to improve Wells turbine performance. Gato et al. [3] and Curran and Gato [4] experimentally investigated the performance of several designs. Kim et al. [5] numerically investigated the effect of blade sweep on the performance of Wells turbine. Setoguchi et al. [6,7] investigated the performance of Wells turbines with various design modifications such as the use of inlet guide vanes and self-rectifying turbines. Brito-Melo et al. [8] numerically investigated the effect of turbine design parameters on the overall plant performance. Dhanasekaran and Govardhan [9] presented computational analysis of Wells turbine performance. Raghunathan et al. [10] studied the effect of inlet conditions on the performance of Wells turbines. The effect of geometric parameters on the performance of Wells turbine such as blade geometry [11], blade setting angle [12], use of end plates [13] and tip clearance [14] have been investigated. In order to enhance the performance of the Wells turbine, some of its rotor blade profiles have been tested under steady flow inlet condition. It has been found by [15] that the optimum blade profile for small-scale Wells turbine, which is installed in wave energy plants such as the navigation buoy [16] (that is, the turbine is operated at a low Reynolds number) is NACA0020. On the other hand, for large-scale Wells turbines, which are installed in wave energy plants such as the LIMPT system [17], (that is, the turbine is operated at a high Reynolds number) it has been found by [19] that the optimum blade profile is NACA0015.

Wells turbines could be equipped with guide vanes to improve turbine efficiency and self starting characteristics. The effect of guide vanes on constant chord [19] and variable chord [16] Wells turbine has also been studied. However, turbines with guide vanes stall before those without guide vanes $[19,20]$. Guide vanes also increase turbine maintenance time and cost and therefore reduce its availability and reliability. Taha et al. [21,22] studied the effect of tip leakage flow on the performance of Wells turbine with uniform tip clearance [21] and also with non-uniform tip clearance [22]. They showed in both studies that tip leakage flow strongly influences the turbine performance and affects the process of turbine stall. Shaaban and Hafiz [23] investigated numerically the effect of duct geometry on the performance of Wells turbine. Thakker and Abdulhadi [24] studied the effect of blade profile and solidity on the performance of large scale Wells turbine under various inlet flow conditions such as sinusoidal and real sea conditions operating under bi-directional unsteady flow conditions.

On the other side, using air turbines to be immersed in water gives promising performance. Such hydrokinetic turbine, one of the most emerging technologies for power generation, has 
gained keen interest of the researchers because of some of the unique properties of water like higher specific weight, higher momentum than air for same velocity etc. Sarma et al. [25] investigated experimentally and computationally hydrokinetic Savonius turbine for low velocity condition. They demonstrated that the performance of such turbine is much higher than conventional Savonius wind turbine at corresponding input values.

According to the previous studies, Wells turbine still suffers from low aerodynamic efficiency, low power produced, and narrow operating range. Consequently, the present paper objective is to improve the performance of Wells turbine. This is achieved by immersing the such turbine inside water. It is notable that using air turbines to be immersed in water is not a new idea. However, the novelty of the present work is to apply such idea on Wells turbine. This gives the privilege of using fluid having higher specific weight than air. The Wells turbine is investigated while having symmetrical NACA 0015 blades. The results are performed by solving numerically the steady 3D incompressible Reynolds Averaged Navier-Stokes equation (RANS) using ANSYS FLYENT v16.2 commercial code. the studied parameters are the flow coefficient, pressure coefficient, torque coefficient and turbine efficiency.

\section{System Layout}

The conventional Wells turbine is shown in Fig. 1a where the oscillating water surface compresses the air when it moves upward and withdraws air when it moves downward. The free water surface thereby, converts the oscillating wave motion into bidirectional air flow through the Wells turbine. On the other side, Fig. 1b introduces the concept of the present work where the Wells turbine is immersed in water.

In Fig. 2 demonstrates the operation of the Wells turbine when using air or water as a working fluid. The flow at the angle of incidence, $\alpha$ will generate lift force L normal to the free stream and a drag force $\mathrm{D}$ in the free stream direction. These forces can be resolved into a tangential component $\mathrm{F}_{\theta}$, which creates torque around the axis of the turbine and an axial component $\mathrm{F}_{x}$ which causes thrust along the axis of the turbine [9]. Thus, for a rotating turbine in oscillating flow, the angle of incidence varies from positive to negative value with the mean value of 0 . As the flow facing the large area of the turbine blade along the chord length of the blade, the drag force faces the large area of the turbine blade. These forces can be resolved into a tangential component $\mathrm{F} \theta$, which creates torque around the axis of the turbine and an axial component $\mathrm{F} x$ which causes thrust along the axis of the turbine [9]. Considering the airfoil being symmetrical, tangential force $\mathrm{F} \theta$ acts in the same direction independently of positive or negative values of the angle $\alpha$. In this way, unidirectional torque from an oscillating flow is created [9].

It is notable to emphasize that the blades of Wells turbine are positioned symmetrically with respect to the plane normal to the central axis. This type of blade positioning makes the turbine non-sensitive to the incoming flow direction (bidirectional flow). The tangential force of the rotor acts only in one direction even though airflow oscillates (bidirectional flow). Consequently, the turbine rotates always in the same direction and runs the electrical generator regardless of the airflow direction. 


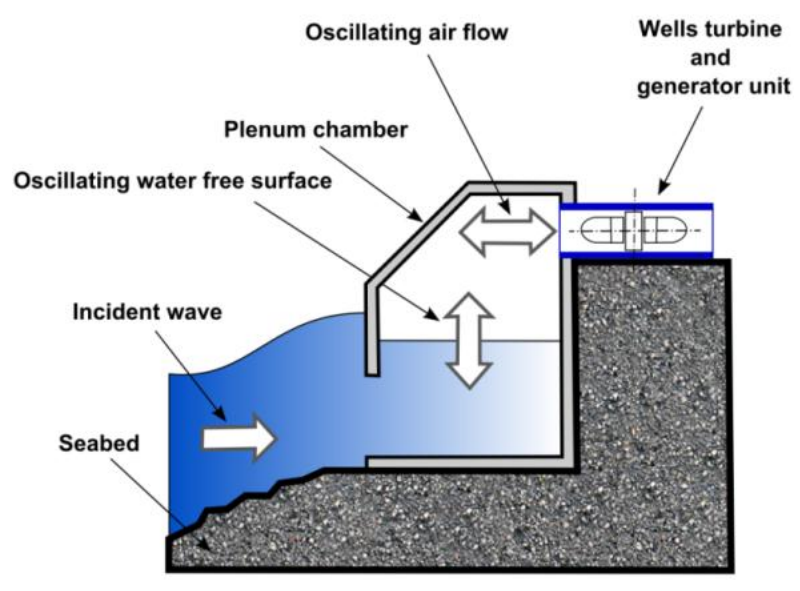

(a) Conventional Wells turbine

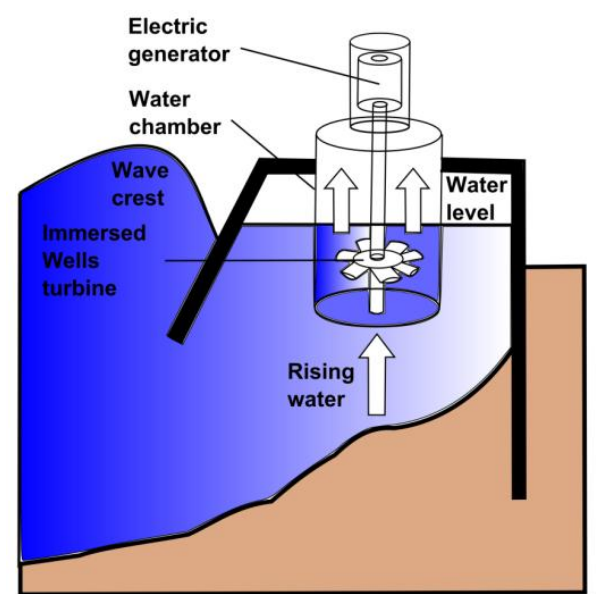

(b) Wells turbine immersed in water

Fig. 1. Schematic cutaway of a Wells turbine.

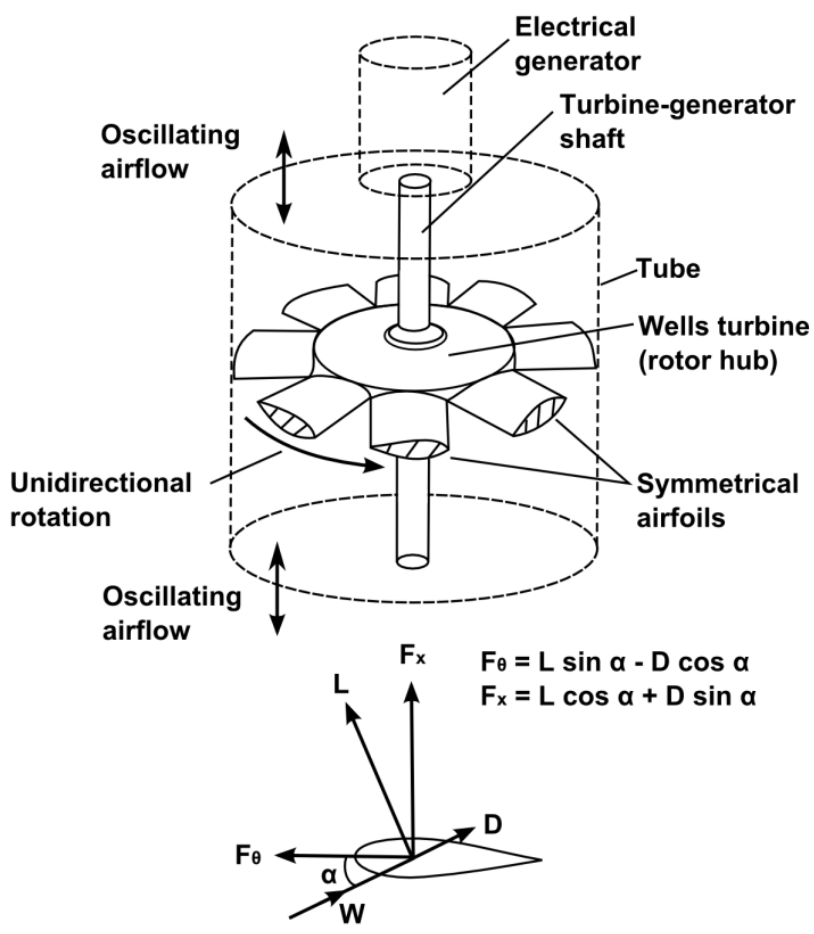

Fig. 2. The Wells air turbine.

Main disadvantages of Wells turbine are; its low aerodynamic efficiency and low power produced, and narrow operating range. In order to enhance the performance of turbine, it is required to reduce its losses. The losses include flow separation and several vortices formation in the passage. The vortices act in terms of flow separation and turbine performance drops. Singular separation or ordinary separation is created by stall in a turbine blade. In the stall condition, the flow is retarded along the wall because of adverse pressure gradient and viscous shear stresses. As a result, the fluid element near the wall can no longer proceed in a forward direction. Several studies have been reported to improve the stalling (or delaying the stall condition) in the compressor and turbine by using circumferential casing grooves which gives a wider operating range and higher power or efficiency [26,27]. 


\section{Computational Methodology}

The Wells turbine and a rotor blade are shown in Fig. 2. The turbine has eight rotor blades and each blade has a chord length of $0.125 \mathrm{~m}$. The blade profile and the stagger angle were NACA0015 and $90^{\circ}$, respectively. Because of the high stagger angle, the blade faces a high drag and the flow starts separating after a certain flow coefficient $\boldsymbol{\phi}$. The other stagger angles do not work in this turbine as the alternating velocity of the air particles hits the blade surfaces from the opposite end of the duct and the turbine rotation becomes unique. The detailed profile is given in Table 1. In the present work the effect of using water as working fluid on Wells turbine performance is numerically investigated by solving the steady $3 \mathrm{D}$ incompressible Reynolds Averaged Navier-Stokes equation (RANS) for a unidirectional water flow. Turbulence is modeled using the realizable $\mathrm{k}-\varepsilon$ model. Enhanced wall functions are used in the near wall flow modeling. The combination of the realizable $\mathrm{k}-\varepsilon$ model and the enhanced wall functions enables good prediction of the aerodynamic performance.

The rotor is modeled using the Moving Reference Frame technique (MRF). The basic governing equations are solved in the absolute frame and discretized by the finite volume method using the CFD code "Fluent" v16.2. The discretization schemes used here are standard scheme for pressure, SIMPLEC algorithm for pressure-velocity coupling and second order upwind scheme for momentum, kinetic energy $(\mathrm{k})$ and turbulence dissipation rate $(\varepsilon)$. The SIMPLEC algorithm used for pressure-velocity coupling reduces the effect of mesh skewness on the final solution. The solutions were considered once the maximum residual values were reached to $10^{-4}$ for the continuity, momentum, and turbulence equations. The turbulent intensity was $5 \%$. Wells turbine rotor geometry used in the present numerical investigation is the one experimentally investigated by Curran and Gato [4].

Table 1 provides the specifications of the investigated Wells turbine. The turbine rotates at a constant angular velocity of $2000 \mathrm{rpm}$. A single blade was used for the computations. The computational domain and the computational mesh are shown in Fig. 3 and Fig. 4, respectively. The computational domain is restricted to one blade-to-blade passage due to turbine symmetry around the axis of rotation. Periodic boundaries are imposed in the tangential direction of the computational domain. The computational domain is limited to four and eight blade chord lengths upstream and downstream the rotor. The grid consists of unstructured tetrahedral elements. Fine grids were employed near the blade surface so that proper boundary layer flow physics can be captured. The total numbers of elements in the domain is 2,580,800. Uniform velocity is applied at the computational domain inlet, while outlet pressure boundary condition is used at the domain outlet. No slip wall conditions are considered for the blades, shroud and hub surfaces. The flow coefficient $\boldsymbol{\phi}$ which is a ratio of fluid velocity to turbine tip velocity was varied from 0.075 to 0.32 and the turbine rotational speed was kept constant ( $2000 \mathrm{rpm}$ ). Hence, the blade tip velocity was constant. The flow velocity was varied from $3 \mathrm{~m} / \mathrm{s}$ to $25 \mathrm{~m} / \mathrm{s}$ to change the flow coefficient $\boldsymbol{\phi}$. Table 2 shows meshing and boundary conditions.

\section{Results and Discussions}

To accept any result obtained from a CFD simulation, grid independency test and validation with existing results are inevitable initial works. The present research work begins with mesh generation, mesh independency, validation of the CFD model with the experimental result and another CFD result and then the effect of working fluid on turbine performance is investigated. 


\subsection{Mesh Independent Study}

A mesh size independence test was performed to ensure minimum influence of mesh size on the CFD results. The mesh size was increased in five gradual steps from 1,440,182 cells to $4,057,831$ cells while maintaining the normalized wall distance $y+<1$ at the same flow coefficient. This test showed that the maximum percentage variation in torque coefficient is $\pm 1.95 \%$, in efficiency $\pm 1.85 \%$ and in pressure drop $\pm 0.8 \%$. Fig. 5 presents the effect of mesh size on simulated turbine efficiency at $\phi=0.15$. The high quality fine mesh with cell size 2,580,800 cells was used throughout the present work where the numerical results are independent of mesh size.

Table1. Turbine model specifications.

\begin{tabular}{ll}
\hline Parameter & Dimension \\
\hline Profile & NACA0015 \\
Number of blades & 8 \\
Blade chord length & $0.125 \mathrm{~m}$ \\
Blade thickness, $\mathrm{t}$ & $15 \%$ of $c$ \\
Hub diameter & $0.4 \mathrm{~m}$ \\
Casing diameter & $0.59 \mathrm{~m}$ \\
Tip clearance & $0.001 \mathrm{~m}$ \\
Solidity & $0.644 \mathrm{~m}$ \\
\hline
\end{tabular}

Table 2. Meshing and boundary conditions.

\begin{tabular}{ll}
\hline Parameter & Description \\
\hline Flow domain & Single blade \\
Interface & Periodic \\
Mesh/Nature & unstructured/tetrahedral \\
Elements & $2,580,800$ \\
Fluid & Air and water \\
Turbulence model & k- realizable \\
Inlet & Velocity \\
Outlet & Pressure \\
Hub & Wall \\
Casing & Wall \\
Blade & Wall \\
Residual criteria & $1 \times 10^{-4}$ \\
\hline
\end{tabular}




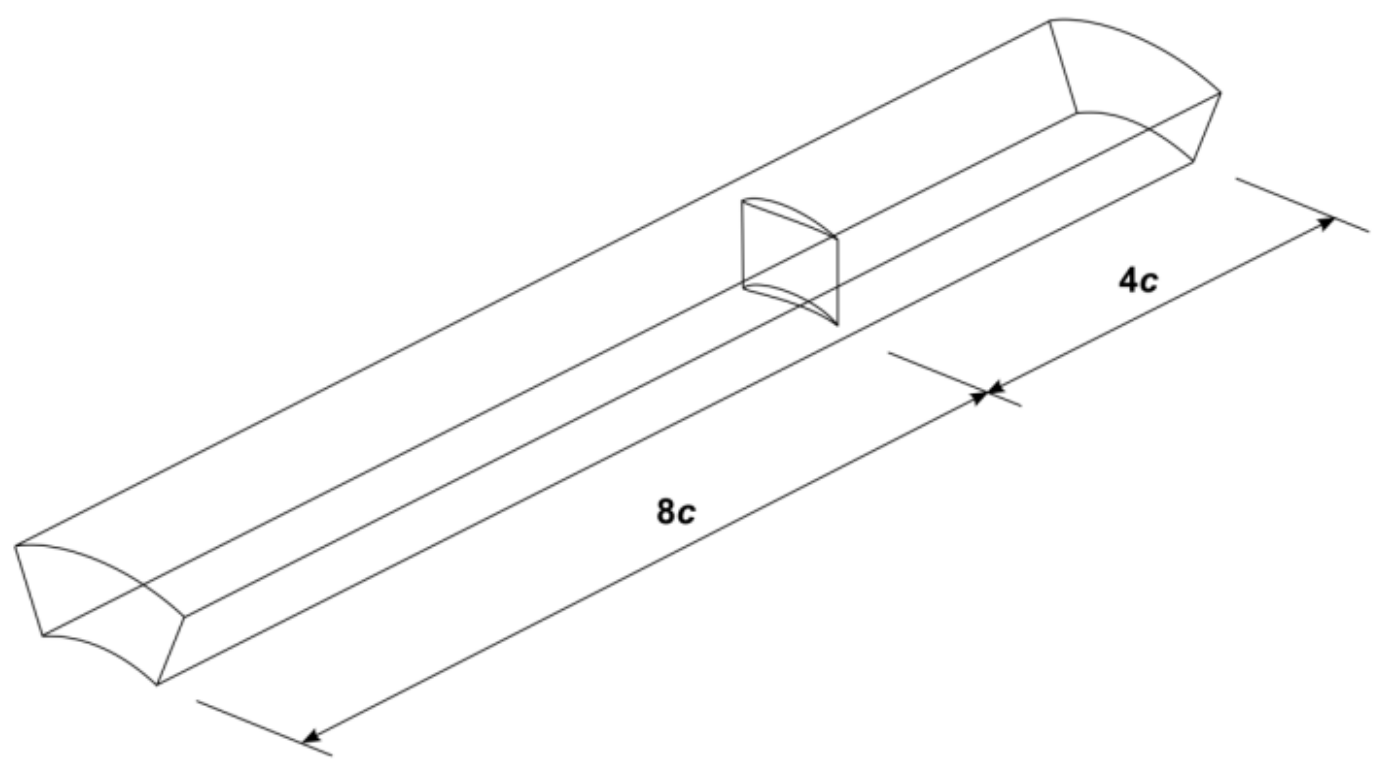

Fig. 3. Perspective view of computational domain.

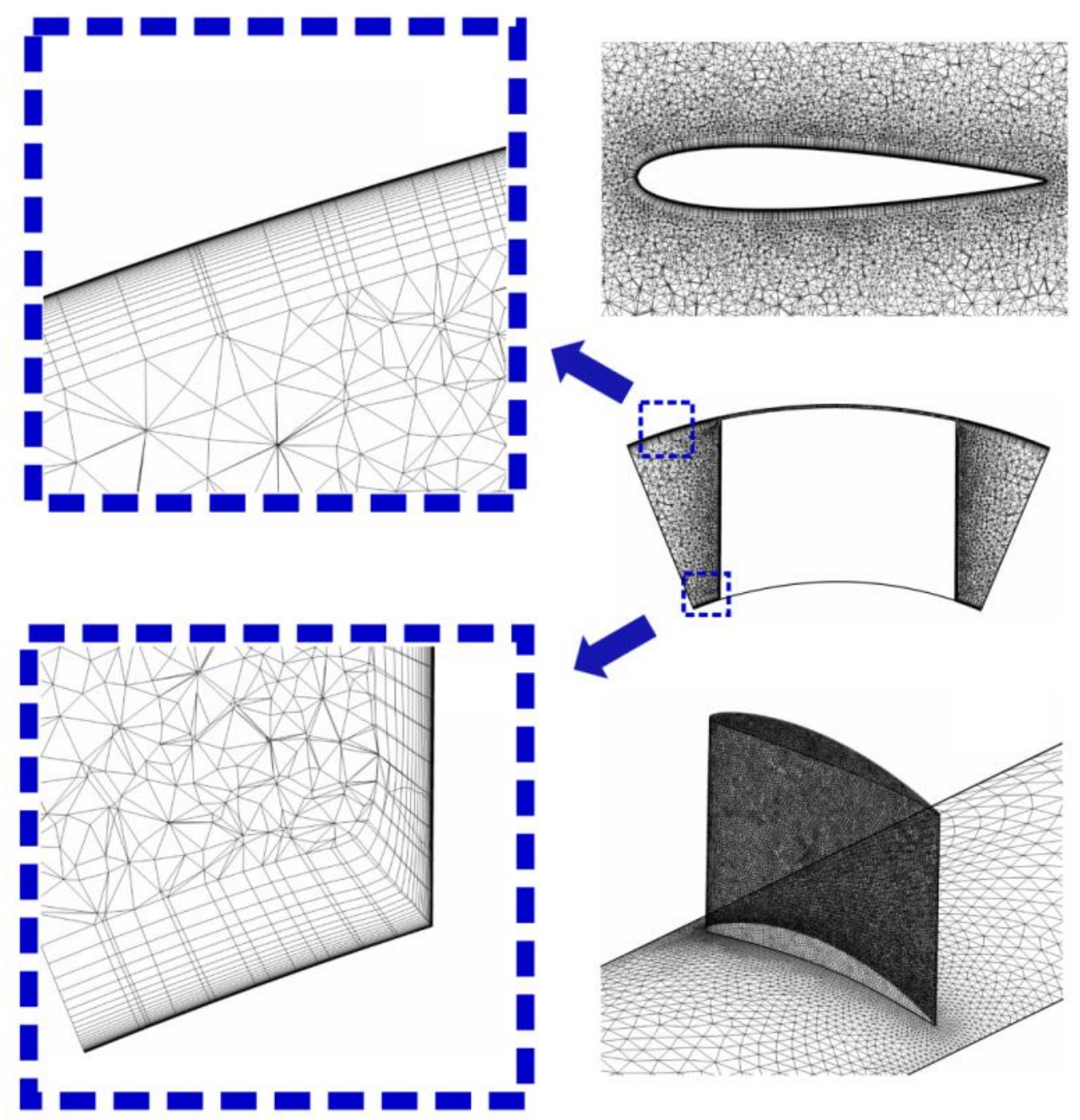

Fig. 4. Unstructured computational mesh. 


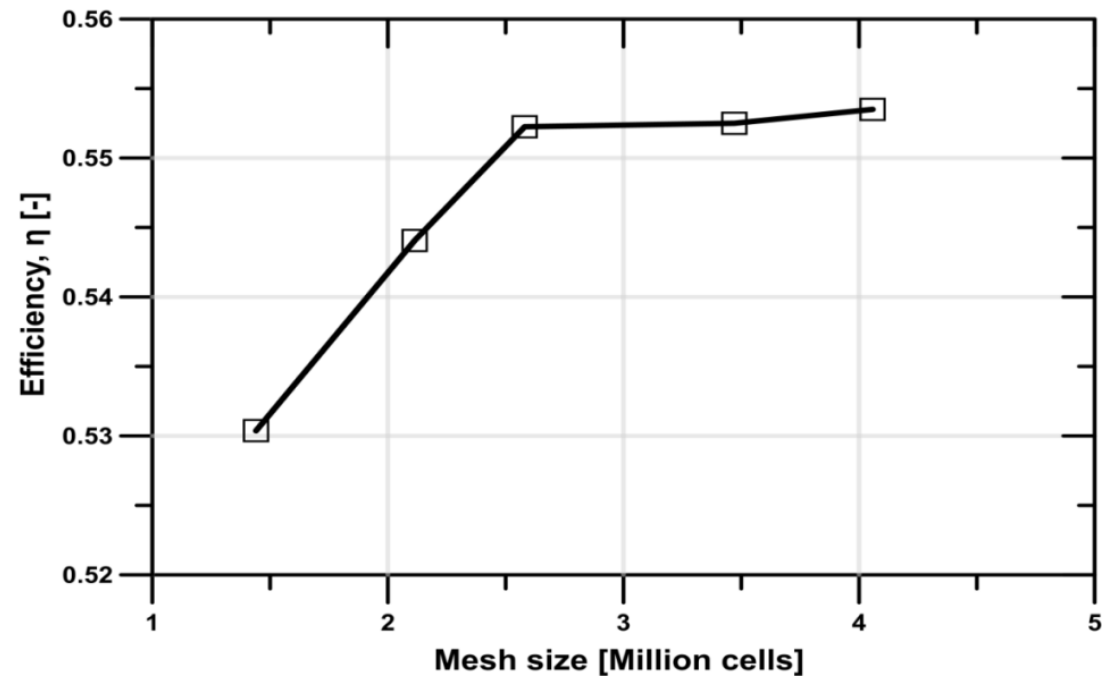

Fig. 5. Variation of turbine efficiency with mesh size at design point

\subsection{Model Validation}

Calculations are carried out at different values of flow coefficient $\phi$, where

$\boldsymbol{\phi}=v / U$

The flow coefficient is varied by varying the axial flow velocity $v$, while keeping the rotational speed $U$ constant. The solution is initialized in the absolute reference frame where all default values are used for the initiation of the solution. All under relaxation factors are also kept at their default values during the solution. In Fig. 6, the computational results were validated with the experimental results of Curran and Gato (1997) [4] and with other CFD results [14,30,31]. The turbine performance is expressed in terms of three non-dimensional coefficients versus with the turbine flow coefficient $\phi$ :

The torque coefficient $\mathrm{CT}$ )

$\mathrm{C}_{\mathrm{T}}=\frac{T}{\rho \omega^{2} R^{5}}$

where $T$ is the rotor torque, $\rho$ is the air density, $\omega$ is the angular velocity and $R$ is the tip radius.

Pressure drop coefficient $\left(\Delta P_{0}^{*}\right)$

$\Delta P_{0}^{*}=\frac{\Delta P_{0}}{\rho \omega^{2} R^{2}}$

where $\Delta P_{0}$ is the total pressure drop.

Turbine efficiency $(\eta)$

$\eta=\frac{T \omega}{\Delta P_{0} Q}$

where $Q$ is the volume flow rate.

Calculations are performed at different values of flow coefficient beginning with a value of $\phi=0.075$. 
A validation curve of the turbine efficiency has been achieved against flow coefficient as shown in Fig. 6 (a). The CFD results were with good agreement compared with the previous experimental work [4], but at the flow coefficient range from 0.1 to 0.15 , the CFD results show a little bit under estimation values. In Fig. 6 (b), the present CFD results show an over estimation of the torque coefficient with respect to the results of [4] at the flow coefficient range from 0.225 to 0.25 . But beyond this range, there was a good agreement of the present CFD results and previous experimental work [4] in wide range of flow coefficient.

However, the present CFD validation was more close to the experimental work [4] compared with the CFD results of $[14,23,28]$ especially in the flow coefficient range from 0.25 to 0.32 , where the CFD results of [30] were so far from both CFD present results and previous work [4, 14,31 ] as shown in Fig. 6 ( $\mathrm{a}$ and $\mathrm{b}$ ). In addition, the CFD results of pressure coefficient were close to the previous experimental and theoretical work of $[4,14,23]$ in the range of flow coefficient from 0.1 to 0.25 the results of [28] were over estimated.

At the flow coefficient range from 0.25 to 0.32 the CFD results were under estimation and the results of $[14,23]$ were over estimated as shown in Fig. 6 (c). Accordingly, The CFD technique has been widely accepted as an analytical tool for Wells turbine. It has the advantage that it can reveal not only the performance of different Wells turbine configurations but also the flow field around the rotor blades. The adopted methodology was validated against experimental data [4]. In summary, a similar approach can be used in other turbo-machinery studies.

\subsection{Analysis of Using Water as a Working Fluid on the Turbine Performance}

The pressure coefficient, torque coefficient and efficiency of the turbine having different working fluids are shown in Fig. 7.

The turbine efficiency inside water compared with its efficiency in air at different values of flow coefficients as shown in Fig. 7(a). There is a slight increase in turbine efficiency at the flow coefficient range from 0.1 to 0.175 . Otherwise, the Wells turbine efficiency enhanced significantly through the range $(0.2-0.3)$.

The maximum percentage increase in turbine efficiency is about 4 times its efficiency in air at flow coefficient of 0.275 . At $50 \%$ turbine efficiency, the wells turbine that is immersed in water has an operating range about 1.5 times its range in air. This is due to the specific weight of water.

In Fig. 7(b), the torque coefficient of the Wells turbine inside water increased considerably as the turbine efficiency. This increase reaches 4.5 times its value in air at flow coefficient of 0.275 . Consequently, the main reason for the increased turbine torque coefficient is the working fluid momentum.

Fig. 7(c) shows that the pressure drop gradually increases as the flow coefficient is increased for the two types of working fluid On the other hand, despite the increase in density and viscosity of the working fluid, the pressure coefficient has not changed through the whole range of operation. 


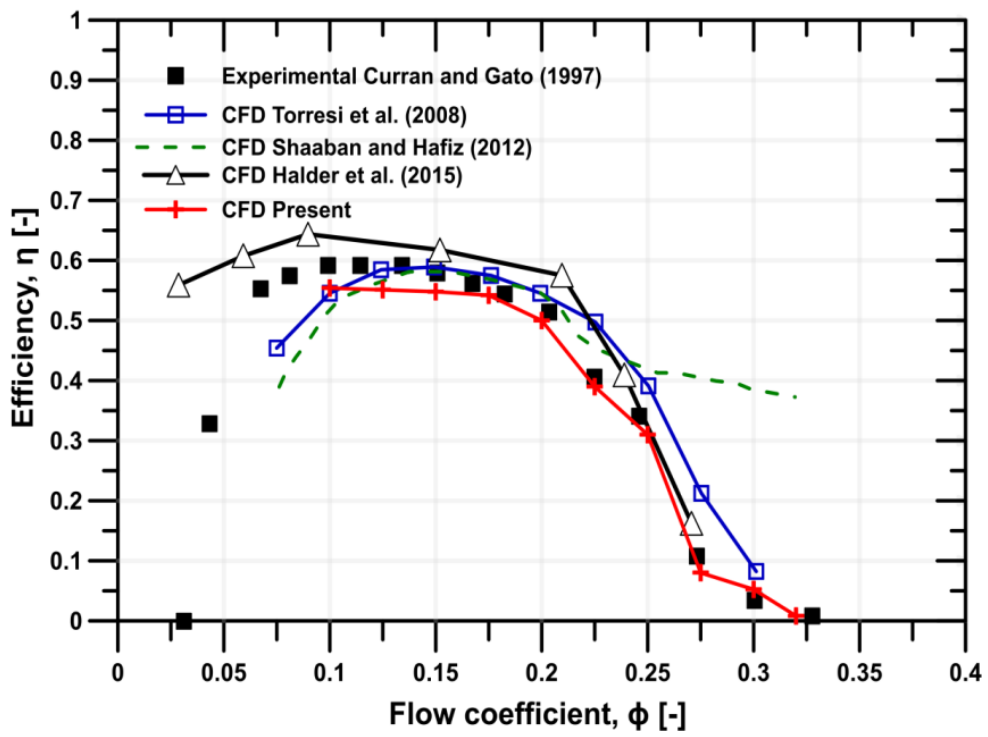

(a)

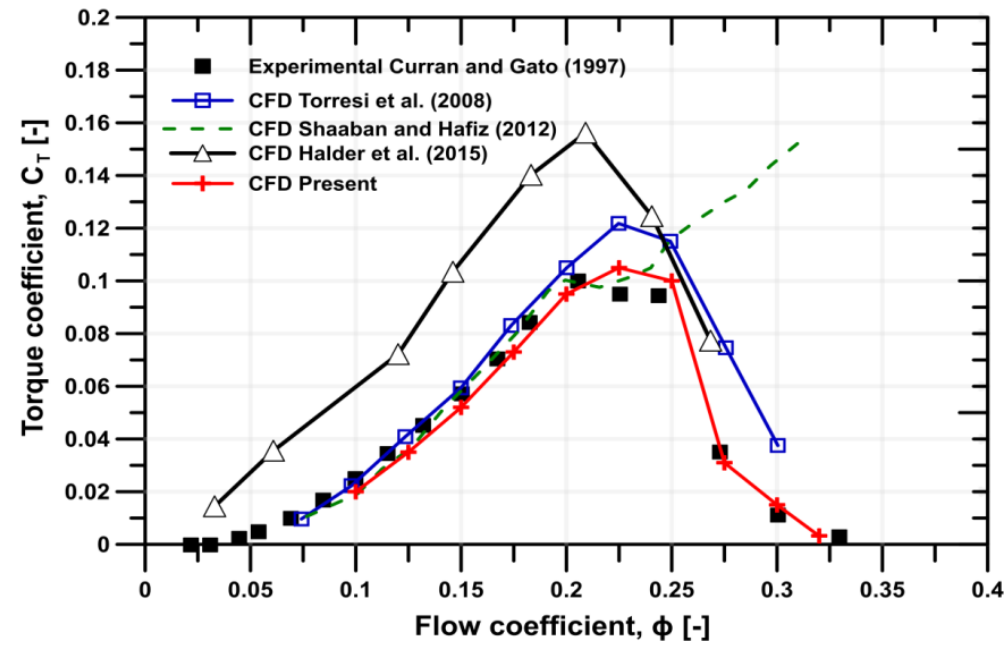

(b)

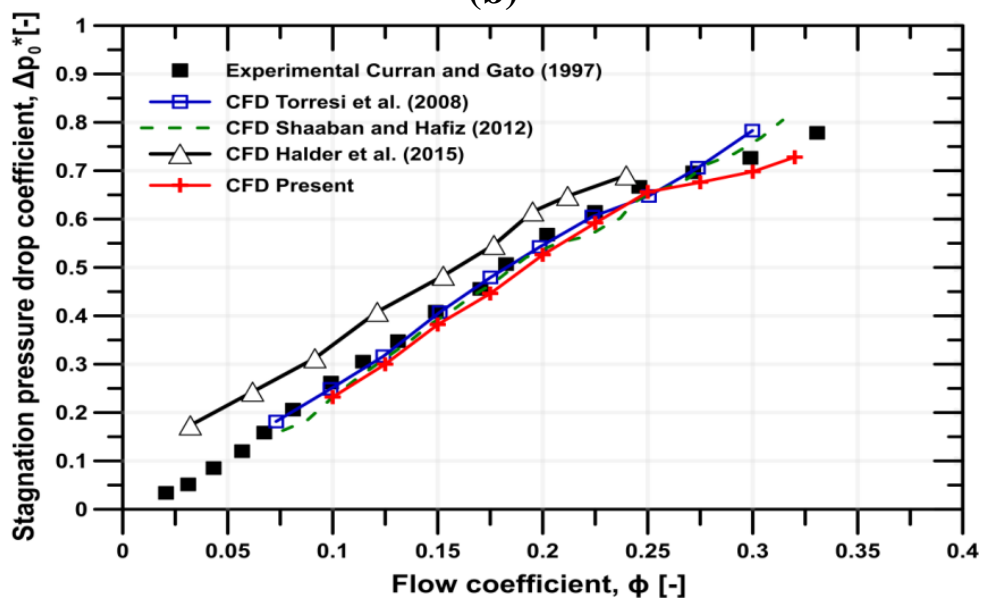

(c)

Fig. 6. Validation with experimental and numerical results for (a) turbine efficiency (b) torque coefficient, and (c) stagnation pressure drop coefficient. 


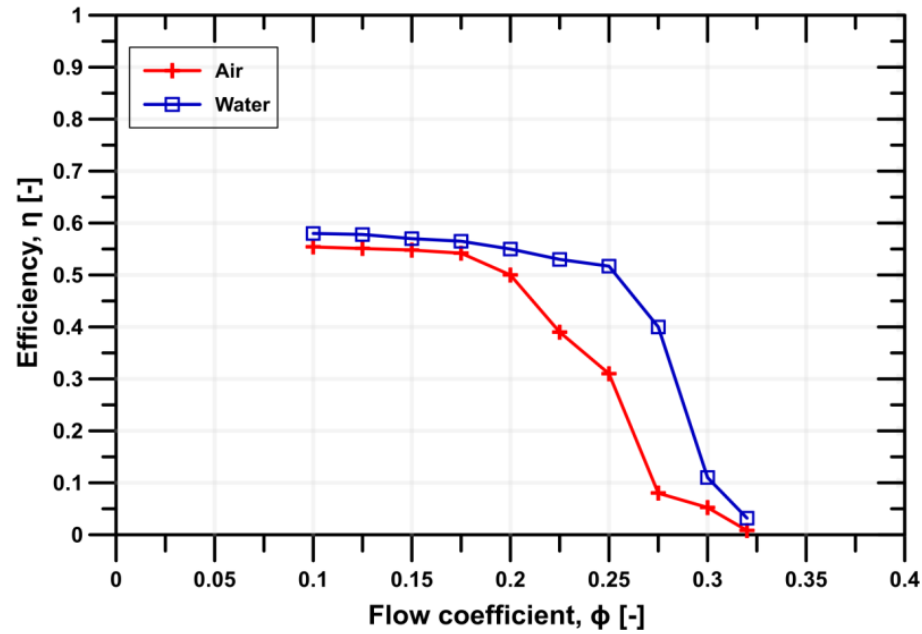

(a)

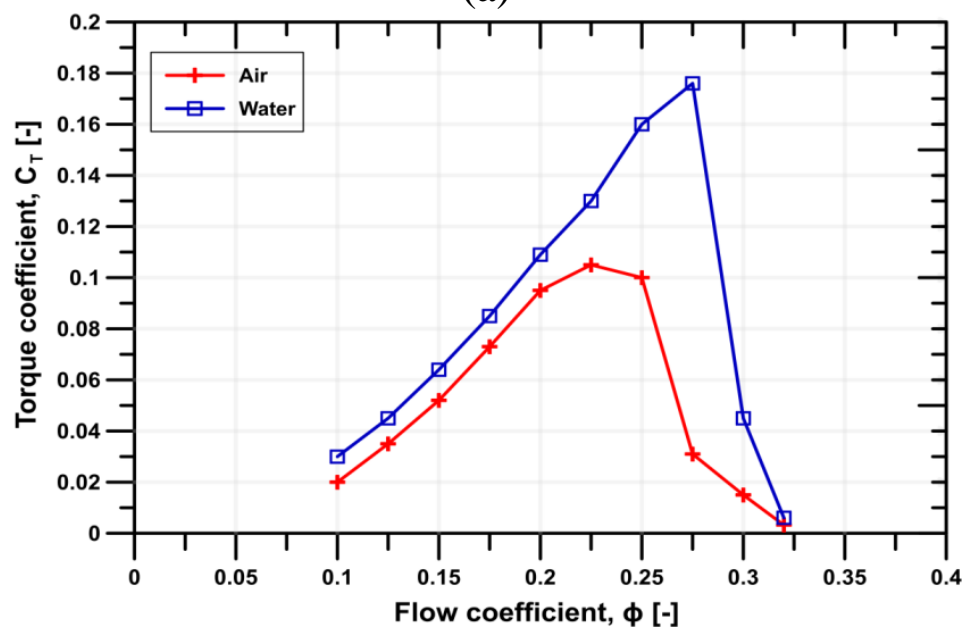

(b)

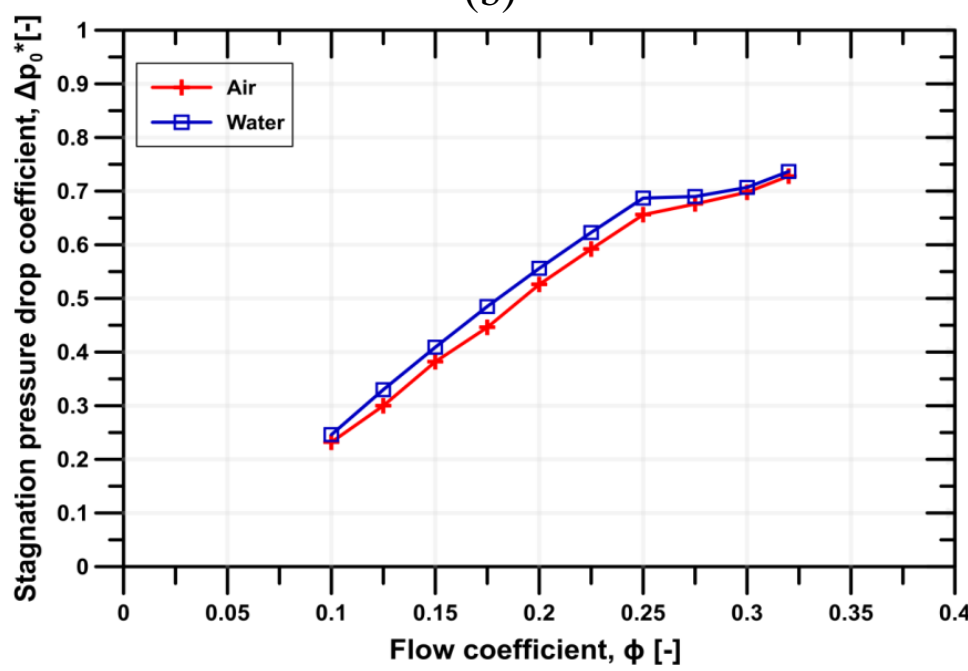

(c)

Fig. 7. Comparative study of two different working fluid for (a) turbine efficiency, (b) turbine torque coefficient, and (c) stagnation pressure drop coefficient. 


\subsection{Effect of Flow Characteristics on Energy Conversion}

A study is performed on the flow-field around the turbine blade to explain the performance of turbine when using water as a working fluid instead of air. Fig. 8 demonstrates the flow patterns around the blades. Such patterns are described by the circumferential velocity

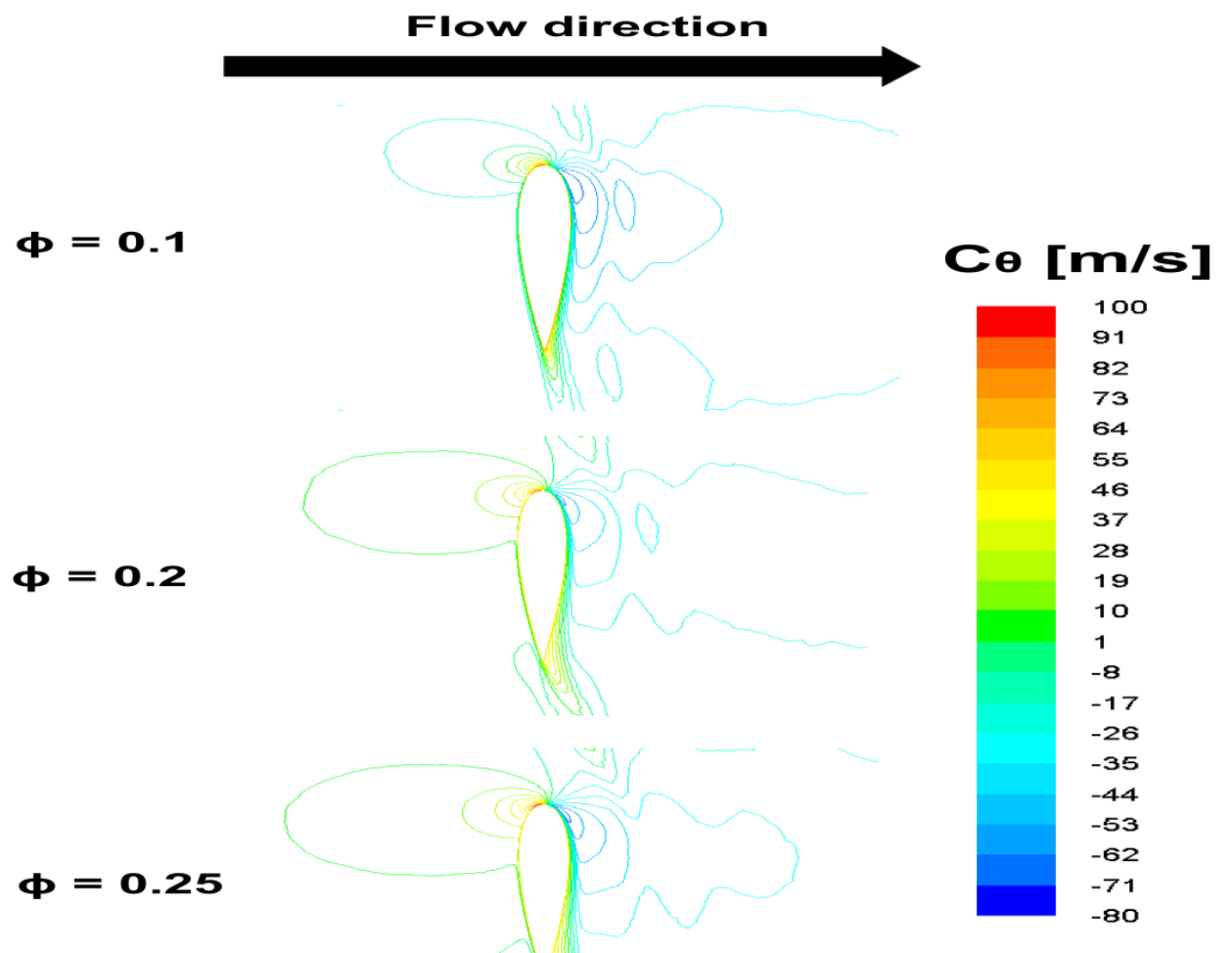

(a)

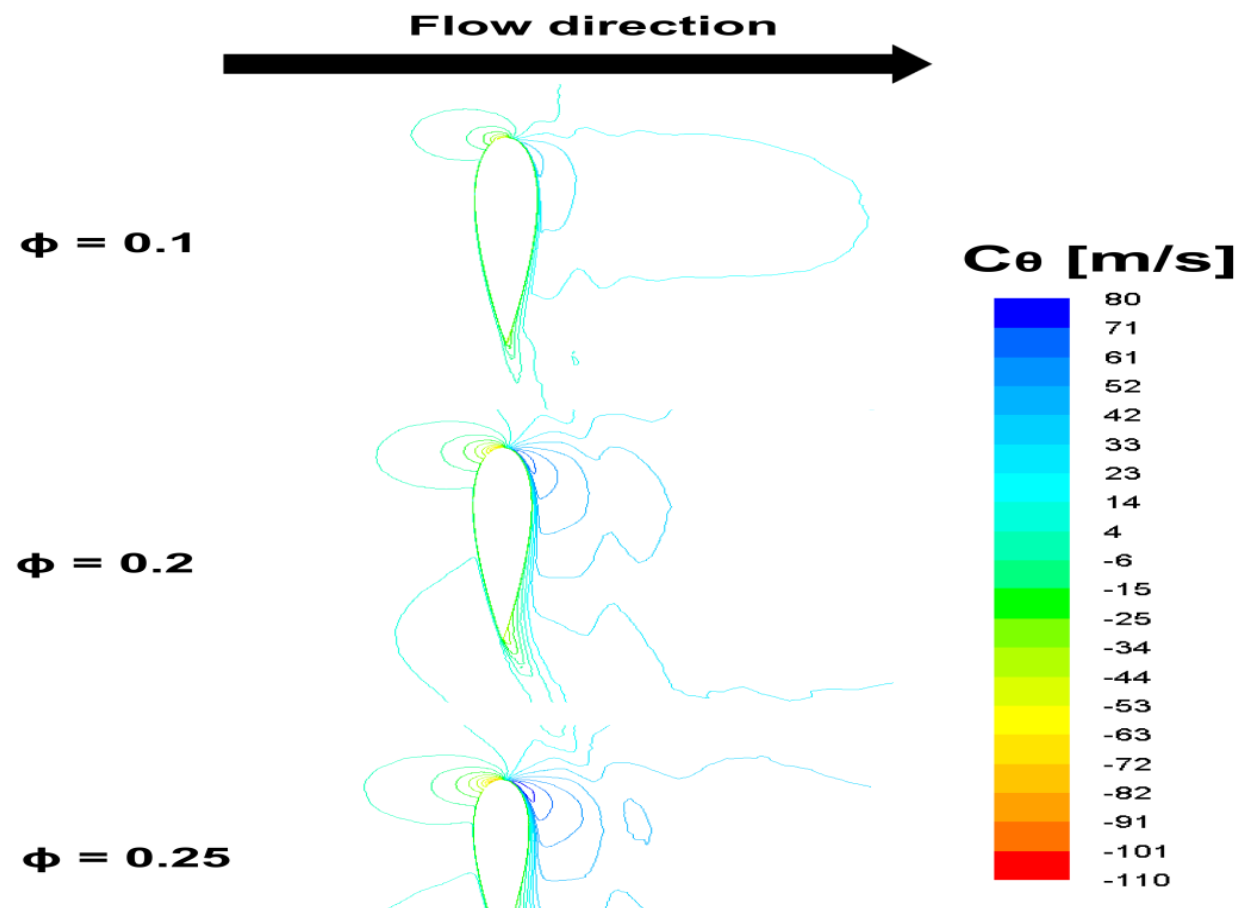

(b)

Fig. 8. Contours of circumferential velocity on a plane of constant radius through $50 \%$ of the flow passage height for (a) air, and (b) water. 
value of flow coefficient $(\phi)$ for air and water wells turbine. The suction side of rotor blades has thin and attached boundary layers at low velocity coefficient. The boundary layer thickness increases with increasing the flow coefficient due to the increase of the angle of attack.

A wake is formed behind the blade trailing edge and deflects slightly towards the axial direction. Figs. 8(a) and 8(b) show comparisons of the flow patterns between the turbines with air and water as a working fluid. From Figs. 8(a) and 8(b), it can be observed that the boundary layer separation of the turbine with air as a working fluid occurs more considerable than that of the turbine with water one. And the flow separation increase with increasing the flow coefficient. As shown in Fig. 6(a) and 6(b) the stall point occur around flow coefficient $\phi=0.2$ when using air as a working fluid but when using water instead of air the stall is delayed as shown in Fig. 7(a) and 7(c) the stall point at $\phi=0.275$.

\section{Conclusions}

The present work introduced a new operational concept of Wells turbine where the turbine is submerged in water. Accordingly, the following conclusions are taken:

1. Wells turbine performance is investigated under steady unidirectional flow conditions using Realizable $\mathrm{k}-\varepsilon$ model where its numerical results were validated. The model is based on 3D steady incompressible Reynolds Averaged Navier-Stokes equation in single rotating reference frame.

2. Substantial improvements of the turbine performance are achieved when using water as working fluid instead of air. It is noticed that the maximum improvement is achieved at flow coefficient of 0.275 .

3. Furthermore, the stall point is also delayed and a wider range of operation with higher efficiency is achieved.

4. The present concept may be a promising issue for further Wells turbine investigations.

\section{References}

[1] Bayoumi AS, Incecik A, El Gamal H, Shalash K. Wave powered water desalination in Egypt. In: Fourteenth international water technology conference (IWTC). Cairo, Egypt; 2010.

[2] Raghunathan S. The Wells air turbine for wave energy conversion. Prog Aerosp Sci 1995;31:335-86 [Elsevier].

[3] Gato LMC, Warfield V, Thakker A. Performance of a high-solidity Wells turbine for an OWC wave power plant. Trans ASME J Energy Resour Technol 1996;118:263-86.

[4] Curran R, Gato LMC. The energy conversion performance of several types of Wells turbine designs. Proc Inst Mech Eng 1996;211(2):133-45.

[5] Kim TH, Setoguchi T, Kaneko K, Raghunathan S. Numerical investigation on the effect of blade sweep on the performance of Wells turbine. Renew Energy 2002;25:235-48 [Elsevier].

[6] Setoguchi T, Takao M, Kaneko K. A comparison of performances of turbines for wave power conversion. Int J Rot Mach 2000;6(2):129-34.

[7] Setoguchi T, Takao M. Current status of self rectifying air turbines for wave energy conversion. Energy Convers Manag 2006;47:2382-96.

[8] Brito-Melo A, Gato LMC, Sarmento AJNA. Analysis of Wells turbine design parameters by numerical simulation of the OWC performance. Ocean Eng. 2002; 29:1463-77 [Elsevier]. 
[9] Dhanasekaran TS, Govardhan M. Computational analysis of performance and flow investigation on well turbine for wave energy conversion. Renew Energy 2005; 30:212947 [Elsevier].

[10] Raghunathan S, Setoguchi T, Kaneko K. The effect of inlet conditions on the performance of Wells turbine. J Energy Resour Technol 1989; 111:37-42.

[11] Kim T, Setoguchi T, Kinoue Y, Kaneko K. Effects of blade geometry on performance of Wells turbine for wave power conversion. J Therm Sci 2001;10(4).

[12] Setoguchi T, Santhakumar S, Takao M, Kim TH, Kaneko K. A modified wells turbine for wave energy conversion. Renew Energy 2003;28:79-91.

[13] Takao M, Setoguchi T, Kinoue Y, Kaneko K. Effect of end plates on the performance of a Wells turbine for wave energy conversion. J Therm Sci 2006;15(4):319-23.

[14] Torresi M, Camporeale SM, Strippoli PD, Pascazio G. Accurate numerical simulation of a high solidity wells turbine. Renew Energy 2008; 33:735-47.

[15] Setoguchi T, Takao M, Itakura K, Mohammed M, Kaneko K, Thakker A. Effect of rotor geometry on the performance of Wells turbine. In: Proceedings of the 13th international offshore and polar engineering conference, 2003, ISOP, Seattle, USA, vol. 1. p. 345-50.

[16] Setoguchi T, Takao M. State of art on self-rectifying air turbines for wave energy conversion. In: Proceedings of the fourth international conference on mechanical engineering, Dhaka, Bangladesh, 2001. p. 117-26.

[17] Boake CB, Whittaker TJT, Folley M, Ellen H. Overview and initial operational experience of the LIMPT wave energy plant. In: Proceedings of the 12th international offshore and polar engineering conference, 2002, ISOPE, Kitakyushu, Japan, vol. 1. p. 586-94.

[18] Takao M, Thakker A, Abdulhadi R, Setoguchi T. Effect of blade profile on the performance of large-scale Wells turbine. Int J Sustain Energy 2006;25(1):53-61.

[19] Thakker A, Dhanasekaran TS, Ryan J. Experimental studies on effect of guide vane shape on performance of impulse turbine for wave energy conversion. Renew Energy 2005;30:2203-19.

[20] Setoguchi T, Kinoue Y, Kim TH, Kaneko K, Inoue M. Hysterestic characteristics of Wells turbine for wave power conversion. Renew Energy 2003;28(13):2113-27.

[21] Taha Z, Sugiyono Sawada T. A comparison of computational and experimental results of wells turbine performance for wave energy conversion. Appl Ocean Res 2010;32:83-90.

[22] Taha Z, Sugiyono TMYS, Ya T, Swada T. Numerical investigation on the performance of Wells turbine with non-uniform tip clearance for wave energy conversion. Appl Ocean Res 2011;33:321-31.

[23] Shaaban S, Abdel HA. Effect of duct geometry on Wells turbine performance. J Energy Convers Manag 2012;61:51-8

[24] Thakker, A. Ã., Abdulhadi, R. The performance of Wells turbine under bi-directional airflow. Renewable Energy 2008; 33, 2467-2474.

[25] Sarma, N. K., Biswas, A., \& Misra, R. D. Experimental and computational evaluation of Savonius hydrokinetic turbine for low velocity condition with comparison to Savonius wind turbine at the same input power. Energy Convers Manag 2014; 83, 88-98.

[26] Hanley BK. Effect of circumferential groove casing treatment parameters on axial compressor flow range [MS thesis]. USA: MIT; 2010.

[27] Houghton T, Day I. Stability enhancement by casing grooves: the importance of stall inception mechanism and solidity. J Turbomach 2012;134(2):021003.

[28] Halder P., Samad A., Casing Treatment of a Wave Energy Extracting Turbine. Aquatic Procedia, 4(Icwrcoe), 516-521. 